\title{
Divinyl chlorophyll a-specific absorption coefficients and absorption efficiency factors for Prochlorococcus marinus: kinetics of photoacclimation
}

\author{
Annick Bricaud ${ }^{1, *}$, Karima Allali $^{1}$, André Morel $^{1}$, Dominique Marie ${ }^{2}$, \\ Marcel J. W. Veldhuis ${ }^{3}$, Frédéric Partensky ${ }^{2}$, Daniel Vaulot ${ }^{2}$ \\ ${ }^{1}$ Laboratoire de Physique et Chimie Marines, Université Pierre et Marie Curie and CNRS, BP 8, \\ 06238 Villefranche-sur-Mer Cedex, France \\ ${ }^{2}$ Station Biologique, Université Pierre et Marie Curie and CNRS, BP 74, 29680 Roscoff, France \\ ${ }^{3}$ Netherlands Institute for Sea Research, PO Box 59, 1790 AB Den Burg, Texel, The Netherlands
}

\begin{abstract}
The photosynthetic prokaryote Prochlorococcus appears to have a high capacity to modify its physiological and optical properties in response to changes in available irradiance. In order to study the time scale of variations in light absorption induced by photoacclimation, 2 strains (MED, clone CCMP 1378, and SARG, unialgal strain) were grown in batch cultures at high $\left(56.7 \mu\right.$ mol quanta $\mathrm{m}^{-2}$ $\left.\mathrm{s}^{-1}\right)$ or low $\left(8.4 \mu \mathrm{mol}\right.$ quanta $\left.\mathrm{m}^{-2} \mathrm{~s}^{-1}\right)$ irradiance. Then the temporal changes over 3 to $4 \mathrm{~d}$ in spectral absorption coefficients, pigment composition, cell number density and size distribution were followed for cultures transferred from high to low irradiance, and vice versa. Both strains experienced significant changes in their divinyl-chlorophyll $a$-specific absorption coefficients $\left(a^{\circ}\right)$ in response to the transfers. For the MED strain, photoacclimation appeared to be achieved within about $40 \mathrm{~h}$ (covering 2 cell generations) for the low to high irradiance transfer, while 3 to $4 \mathrm{~d}$ (corresponding to 1 doubling of the population) were necessary for the high to low irradiance transfer. For the SARG strain transferred from high to low irradiance, in spite of a rapid change in absorption during the first $25 \mathrm{~h}$ (i.e. within the same cell generation), full photoacclimation was not achieved after $3 \mathrm{~d}$. The efficiency factors for absorption, $\overline{Q_{a}}(\lambda)$, and the $a^{\cdot}(\lambda)$ coefficients, were reconstructed from theory at the different photoacclimation stages from the cell characteristics, i.e. intracellular concentrations of the various pigments and cell size distribution. This permitted the determination of the parameters which are mainly responsible for the observed changes. The $\overline{Q_{a}}(\lambda)$ values (and therefore the package effect) are enhanced at low irradiance by 2 effects resulting from photoacclimation: the increase of the intracellular concentration of divinylchlorophyll $a$, and (for the SARG strain only) the increase of the intracellular concentration of chlorophyll $b$. In addition, the presence of zeaxanthin, in stable amounts within the cells whatever the irradiance, enhances the $\vec{Q}_{\mathrm{a}}(\lambda)$ values for all light conditions, and thus 'moderates' its variations with irradiance. Contrary to what is commonly admitted because of its tiny size, the absorption efficiency of Prochlorococcus (per pigment unit) is not always maximal, but can be reduced by 20 to $25 \%$ at low irradiances, such as those prevailing in the lower part of the euphotic zone. This reduction directly affects the amount of absorbed energy usable for photosynthesis.
\end{abstract}

KEY WORDS: Prochlorococcus · Prochlorophyta - Optical properties A Absorption Photoacclimation

\section{INTRODUCTION}

The photosynthetic prokaryote Prochlorococcus discovered some years ago in the Sargasso Sea (Chisholm et al. 1988), has been found to be widely distributed in

\footnotetext{
•E-mail: bricaud@obs-vlfr.fr
}

oceanic waters, and to account for a significant part of the biomass as well as the primary production, particularly in oligotrophic and mesotrophic ecosystems (e.g. Goericke \& Welschmeyer 1993, Campbell et al. 1994; see also review by Partensky et al. 1999). Prochlorococcus is observed over a wide irradiance range, approximately 1 to 1500 umol quanta $\mathrm{m}^{-2} \mathrm{~s}^{-1}$ (Parten- 
sky et al. 1996). This ubiquity can be partly explained by the coexistence of several distinct populations within the water column (Campbell \& Vaulot 1993) In particular, the MED and SARG strains, isolated from Mediterranean surface waters and from the deep chlorophyll maximum of the Sargasso Sea, respectively, appear to be phylogenetically distant (Palenik \& Haselkorn 1992) and differ in their pigmentation and optical and photosynthetic properties (Partensky et al. 1993, Moore et al. 1995). These studies, however, also suggest that each of these strains exhibits a high capacity for photoacclimation, i.e. for reversible physiological changes occurring in response to light variations. Drastic changes in the intracellular divinylchlorophyll a (DV-chl a) and accessory pigment contents were observed when cultures were submitted to various irradiances, and resulted in modifications in the spectral chl-specific (i.e. normalized to the DV-chl a concentration) absorption coefficients, $a^{\bullet}(\lambda)$ (Partensky et al. 1993, Moore et al. 1995). In the field, similar changes were also recorded, such as those resulting from the decrease in irradiance with increasing depth (Veldhuis \& Kraay 1990, Partensky et al. 1996). What has not yet been documented, however, is the time scale of such photoadaptative changes. Knowledge of these time scales is of ecological significance and could contribute, as suggested by Babin et al. (unpubl.), to an explanation of the dominance of Prochlorococcus in oligotrophic waters.

The absorption coefficient is directly related to the dimensionless efficiency factor for absorption $\left(Q_{a}\right)$, i.e. the ratio of the energy absorbed within a mean cell (representative of the population) to the energy incident on its geometrical section. These efficiency factors can be reconstructed from the cell characteristics, namely the intracellular concentrations of the various pigments and the cell size distribution, using the anomalous diffraction approximation (van de Hulst $1957)$, and then converted into $a^{*}(\lambda)$ coefficients. Note that such an approach is different from the reconstruction technique described by Bidigare et al. (1987), and afterwards used in various studies (Smith et al. 1989, Bidigare et al. 1990, Moore et al. 1995). Contrary to the Bidigare et al. technique, based solely on the pigment composition and the unpackaged absorption coefficients of individual pigments, the reconstruction proposed in this study, via the $Q_{a}$ factors, accounts for the package effect, if any.

Such reconstruction allows us to determine whether the observed absorption properties are fully consistent with, and predictable from, cell characteristics. It is also aimed at determining the respective contributions of the factors responsible for changes in the absorption properties of Prochlorococcus. Two factors are of particular importance with respect to photosynthetic performance. On the one hand, the presence of zeaxanthin, the dominant accessory pigment in Prochlorococcus, increases the amount of absorbed energy without increasing carbon fixation, because the absorbed energy is not transferred to the photosystems (e.g. Demmig-Adams 1990). On the other hand, if the absorption efficiency of the minute Prochlorococcus cells $(0.6$ to $0.7 \mu \mathrm{m})$ is maximal owing to an insignificant package effect, this should result in optimized photosynthetic capacities. A minimal package effect, however, requires not only small cell size but also weak intracellular pigment concentrations (Morel \& Bricaud 1981). Moore et al. (1995) concluded, from a comparison between experimental and reconstructed (unpackaged) a" spectra for MED and SARG cultures, that the package effect was negligible for the irradiance range considered. This assumption is also frequently made for the natural populations of oligotrophic waters (e.g. Lindley et al. 1995). A recent study in the Equatorial Pacific, however, suggests that this is not always the case, particularly at the low irradiances prevailing at the bottom of the euphotic zone (Allali et al. 1997).

The aims of this paper are therefore (1) to describe the kinetics of variations in $a^{*}(\lambda)$ for Prochlorococcus cultures acclimated to a given irradiance and then transferred to a different irradiance; (2) to reconstruct the $a^{*}(\lambda)$ spectra from the cell characteristics, and to determine how the various parameters contribute to the temporal variations in $a^{*}(\lambda)$; and (3) to evaluate the importance of the package effect at the different photoacclimation stages. Experiments were conducted as part of a workshop aimed at studying the effects of photoacclimation on physiological, optical and photosynthetic parameters of Prochlorococcus. Both the MED and SARG strains were studied, so as to detect possible deviations in behavior with respect to the above issues. A list of notation is provided (Table 1).

\section{MATERIALS AND METHODS}

Strains and cultures. Two Prochlorococcus mariunus isolates, MED (clone CCMP 1378) and SARG (a unialgal strain), were used in this study. Details of their origin, isolation methods and culture media are given in Partensky et al. (1993). Batch cultures were grown at 21 $\pm 1^{\circ} \mathrm{C}$ in a modified K/10 medium (Keller et al. 1987), under continuous blue light provided by daylight fluorescent tubes (Silvania) with blue plastic filters (LEE no. 183). Cultures were not axenic, and the number of heterotrophic bacteria varied between 9 and $38 \%$ of the total cell number for the experiments presented here. The experiments, identified respectively as $\mathrm{H} \rightarrow \mathrm{L}$ and $\mathrm{L} \rightarrow \mathrm{H}$, consisted of transferring high-light $(56.7 \mu \mathrm{mol}$ 
Table 1. Definition of mathematical symbols and associated units

\begin{tabular}{|c|c|c|}
\hline Symbol & Definition & Unit \\
\hline$\lambda$ & Wavelength & $\mathrm{nm}$ \\
\hline $\mathrm{OD}(\lambda)$ & Optical density & - \\
\hline$r$ & Optical pathlength & $\mathrm{m}$ \\
\hline$N / V$ & Cell number density & $m^{-3}$ \\
\hline$\mu$ & Specific growth rate & $d^{-1}$ \\
\hline$a(\lambda)$ & Absorption coefficient & $\mathrm{m}^{-1}$ \\
\hline$a^{\cdot}(\lambda)$ & Divinyl-chl a-specific absorption coefficient & $\mathrm{m}^{2} \mathrm{mg}^{-1}$ \\
\hline$[D V-c h l a]$ & Divinyl-chl a concentration & $\mathrm{mg} \mathrm{m} \mathrm{m}^{-3}$ \\
\hline$D$ & Cell diameter & $\mu m$ \\
\hline$F(D)$ & Size distribution function & - \\
\hline$D_{3}$ & Mean diameter of the population (computed with respect to the volume) & $\mu \mathrm{m}$ \\
\hline$c_{1, \mathrm{p}}$ & Intracellular concentration of the pigment $\mathrm{p}$ & $\mathrm{kg} \mathrm{m}^{-3}$ \\
\hline$C_{p}$ & Concentration of the pigment $\mathrm{p}$ in the suspension & $\mathrm{mg} \mathrm{m} \mathrm{m}^{-3}$ \\
\hline$a_{c m}(\lambda)$ & Absorption coefficient of the cell material & $\mathrm{m}^{-1}$ \\
\hline$\rho^{\prime}$ & Optical thickness of a spherical cell corresponding to absorption along a diameter & \\
\hline$a^{*}$ sol,p $(\lambda)$ & Weight-specific absorption coefficient of the pigment $p$ & $\mathrm{~m}^{2} \mathrm{mg}^{-1}$ \\
\hline$a^{*}$ sol $(\lambda)$ & Unpackaged absorption coefficient of the cell material & $\mathrm{m}^{2} \mathrm{mg}^{-1}$ \\
\hline$Q_{a}(\lambda)$ & Efficiency factor for absorption & - \\
\hline 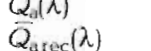 & Etticiency factor for absorption, averaged for the polydispersed population & - \\
\hline $\begin{array}{l}Q_{\text {arec }}(\lambda) \\
a_{\text {res }}(\lambda)\end{array}$ & Reconstructed efficiency factor for absorption (averaged) & $m^{-1}$ \\
\hline$a^{*}{ }_{\operatorname{rec}}(\lambda)$ & Reconstructed DV-chl a-specific absorption coefficient & $\mathrm{m}^{2} \mathrm{mg}^{-1}$ \\
\hline $\bar{Q}_{a} \cdot\left(\lambda_{i}\right)$ & Package effect index $\left[=a^{*}(\lambda) / a^{*}{ }_{\text {sol }}(\lambda)\right]$ & - \\
\hline
\end{tabular}

quanta $\mathrm{m}^{-2} \mathrm{~s}^{-1}$ )-acclimated cultures to low irradiance (8.4 $\mu \mathrm{mol}$ quanta $\left.\mathrm{m}^{-2} \mathrm{~s}^{-1}\right)$, and vice versa. Resulting changes in optical parameters were followed during 3 to $4 \mathrm{~d}$. The control cultures, simultaneously maintained at high and low irradiance, are identified as HH and LL. Most of the measurements were made in exponential phase of cell growth (see Fig. 3). Some, however, were discarded because nutrient limitation began to occur (late phases of the MED HH and MED L $\rightarrow \mathrm{H}$ experiments) or because dead cells appeared in a significant amount (SARG LL and $\mathrm{L} \rightarrow \mathrm{H}$ experiments). Replicate cultures were grown for each experiment, and cell countings of these cultures showed that the cell growth rate was reproducible. Because of volume limitations, optical measurements could not be performed on these replicate cultures. However, the optical variability is believed to be weak between cultures with similar cell growth rates.

Absorption coefficients. Optical densities of Prochlorococcus suspensions were determined with a double-beam spectrophotometer (Perkin-Elmer Lambda 19) equipped with an integrating sphere, in reference to the filtrate of the suspension $(0.22 \mu \mathrm{m}$ Millipore Millex-GS filter). Before measurement, samples were concentrated by centrifugation $(10 \mathrm{~min}$ at $5000 \mathrm{rpm}$ $[2000 \times g]$ ] to obtain sufficiently high optical densities. When absorption was also measurable without concentration, it was possible to check that centrifugation does not induce a modification of the spectral shape. Absorption coefficients, $a(\lambda)\left(\mathrm{m}^{-1}\right)$, were obtained as

$$
a(\lambda)=2.3 \bigcirc \mathrm{D}(\lambda) / r
$$

where $r(=0.01 \mathrm{~m})$ is the pathlength of the cuvette. For all samples, the apparent absorption observed between 790 and $800 \mathrm{~nm}$ (originating from the artifactual contribution of backscattering, which is significant for very small cells) was subtracted from the spectral absorption coefficients. No correction was made for absorption by heterotrophic bacteria, which is typically

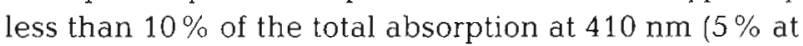
$445 \mathrm{~nm}$ ) for bacterial numbers up to $50 \%$ of the total cell number, and becomes insignificant at longer wavelengths (Morel et al. 1993). The chl-specific absorption coefficients, $a^{\cdot}(\lambda)$, expressed in $\mathrm{m}^{2} \mathrm{mg}^{-1}$ DV-chl $a$, were obtained from the absorption coefficients, $a(\lambda)$, according to

$$
a^{*}(\lambda)=a(\lambda) /[D V-\operatorname{chl} a]
$$

where [DV-chl a] is the DV-chl a concentration (in $\mathrm{mg} \mathrm{m}^{-3}$, determined before concentration, and then multiplied by the ratio of cell numbers before and after concentration). These $a^{*}(\lambda)$ spectra were found to be affected by some erratic variations (approximately $\pm 20 \%$ ) resulting from the concentration procedure, which obscured the actual trends of $a^{*}(\lambda)$ with time. These variations were minimized by setting the height of the red absorption band las measured above a base-

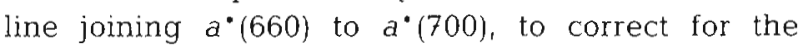
enhancement due to the presence of chl $b$ and/or DVchl $b]$ to the height of the absorption band of DV-chl $a$ 
in solution $\left(0.0173 \mathrm{~m}^{2} \mathrm{mg}^{-1}\right.$ DV-chl a; see Fig 1). Such a normalization presumes that the package effect is insignificant at the red wavelengths, an assumption which will be justified a posteriori.

Cell number densities and size distributions. Cell number densities, $N / V$, and bacteria concentrations were determined using a Coulter EPICS $V$ flow cytometer equipped with a $5 \mathrm{~W}$ Argon laser, as described in Cailliau et al. (1996). Samples concentrated by centrifugation were fixed with paraformaldehyde $(0.5 \%)$, frozen in liquid nitrogen and stored at $-80^{\circ} \mathrm{C}$ (Vaulot et al. 1989) for later analysis. Cell loss resulting from preservation (approximately $7 \%$ of cells) was empirically corrected for by comparing cell counts on 252 samples before and after fixation. Cell number densities varied between $3.8 \times 10^{6}$ and $72 \times 10^{6}$ cell ml ${ }^{-1}$ before centrifugation, and were about 5 -fold higher after centrifugation.

Cell size distribution functions, $F(D)$ (where $D$ is the diameter of the volume-equivalent sphere), were determined using a Coulter Multisizer II (256 channels) equipped with a $15 \mu \mathrm{m}$ orifice. Before each measurement, filtered seawater was circulated for 3 to $5 \mathrm{~min}$ inside a closed circuit containing a $0.2 \mu \mathrm{m}$ filter. This maintained the remnant particle number inside the counting window below $3 \%$ of the minimum particle number to be counted. The influence of noise in the first channels was minimized by adjusting $F(D)$ to a log-normal law by least-square fit. The presence of heterotrophic bacteria in cultures was assumed to affect only the number densities, and not the shape of $F(D)$. This approximation, similar to that made by Morel et al. (1993), is believed to be justified as all observed size distributions were unimodal. Therefore, $F(D)$ was considered only in relative values, and scaled by setting its integral to $N / V$, as measured by flow cytometry.

Pigment concentration measurements. Pigments were extracted and analyzed using a Waters Associated HPLC instrument with a photodiode array detector (Model 991), according to Veldhuis \& Kraay (1990) and Kraay et al. (1992). Identified pigments were DVchl $a$, DV-chl $b+\operatorname{chl} b$, chl $c_{3}$-like, zeaxanthin, $\alpha$ carotene, cryptoxanthin and an unknown carotenoid, the latter 2 being present only as traces. Monovinyl (MV)- and DV-chlorophylls a and $b$ were separated by applying the silica-based normal phase analysis (Veldhuis \& Kraay 1990). MV-chl a was always absent in both strains, while MV-chl $b$ was present in the SARG strain only, as already observed in previous studies (Partensky et al. 1993, Moore et al. 1995). The DV-chl a and DV-chl $b+c h l b$ concentrations were multiplied by 1.06 and 1.09 , respectively, to correct for fluorescence emitted by these pigments and detected by the diode array system. This empirical correction is based on the study of Latasa et al. (1996), who observed that in such systems, fluorescence emission artifactually decreases chl $a$ and chl $b$ concentrations by, on average, 6 and $9 \%$, respectively.

Reconstruction of absorption efficiency factors and coefficients from cell characteristics. For a population polydispersed in size, the mean efficiency factors for absorption, $\bar{Q}_{d}(\lambda)$, are related to the absorption coefficients $a(\lambda)$ via the relationship:

$$
a(\lambda)=(\pi / 4) \overline{Q_{\mathrm{d}}}(\lambda) \int_{0}^{\infty} F(D) D^{2} \mathrm{~d} D
$$

Under the assumption that cells are spherical and homogeneous with respect to the refractive index, the $\bar{Q}_{a}(\lambda)$ values can be 'reconstructed' from the cell characteristics using the anomalous diffraction approximation (van de Hulst 1957). For a given diameter $D$ and a given wavelength, $Q_{\mathrm{a}}$ is obtained from $D$ and the absorption coefficient of the cell material, $a_{\mathrm{cm}}(\lambda)$, using the equation:

$$
Q_{a}\left(\rho^{\prime}\right)=1+2 \exp \left(-\rho^{\prime}\right) / \rho^{\prime}+2\left[\exp \left(-\rho^{\prime}\right)-1\right] /\left(\rho^{\prime 2}\right)
$$

in which $\rho^{\prime}=a_{c m} D$. The mean factors, denoted $\bar{Q}_{\text {в rec }}(\lambda)$, are then obtained by averaging over $F(D)$ (see e.g. Morel \& Bricaud 1986). The $a_{c m}(\lambda)$ coefficients were here computed from the intracellular concentrations of the various pigments, $c_{i, p}$, and their specific absorption coefficients, $\partial^{*}{ }_{\text {sol,p }}(\lambda)$, according to:

$$
a_{c m}(\lambda)=\sum c_{1, p} a^{\cdot}{ }_{\text {sol, }}(\lambda)
$$

where $c_{1, p}$ is the ratio of the concentration of this pigment within the suspension, $C_{p}$, to the volume concentration of suspended cells:

$$
C_{\mathrm{i}, \mathrm{p}}=C_{\mathrm{p}}\left[(\pi / 6) \int_{0}^{\infty} F(D) D^{3} \mathrm{~d} D\right]^{-1}
$$

The $a^{*}{ }_{\text {sol,p }}(\lambda)$ spectra were estimated by scaling the absorption spectra of individual pigments measured (in relative values) by HPLC ( $\mathrm{H}$. Claustre pers. comm.) to the weight-specific absorption coefficients proposed by Goericke \& Repeta (1993), and then shifting the positions of maxima in solvents to match the in vivo positions, as in Bidigare et al. (1990). These spectra (Fig. 1) compare well with those obtained using a similar procedure by Moore et al. (1995). A summary of the procedure used to reconstruct the $\overline{Q_{a}}(\lambda)$ spectra, and then the $a^{*}(\lambda)$ spectra, is shown in Fig. 2 .

\section{RESULTS AND DISCUSSION}

\section{Effects of light transfers on DV-chl a-specific absorption coefficients}

\section{MED strain}

The $a^{*}(\lambda)$ spectra of the MED strain all exhibited the absorption bands of DV-chl a around 445 and $672 \mathrm{~nm}$, 


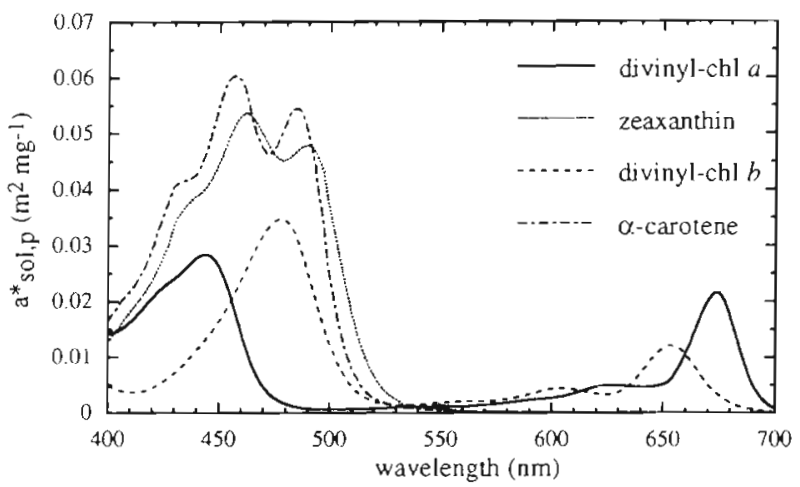

Fig. 1. In vivo weight-specific absorption coefficients for the main pigments of Prochlorococcus marinus, obtained by scaling HPLC-generated absorption spectra (courtesy of $\mathrm{H}$ Claustre) to weight-specific absorption coefficients at given wavelengths, and then shifting absorption bands to their in vivo positions (see 'Materials and methods'). The chl $c$-like pigment was not considered, as its concentration was $<3 \%$ of the divinyl-chl a concentration for all experiments

a band around $490 \mathrm{~nm}$ (due to zeaxanthin and, to a much lesser extent, $\alpha$-carotene) and an almost zero absorption between 530 and $590 \mathrm{~nm}$ (Fig. 3a,c). Because the DV-chl $b$ content was low (see Fig. $6 \mathrm{~b}, \mathrm{~d}$ ), its absorption bands around 480 and 650 to $655 \mathrm{~nm}$ were virtually absent.

For the MED $\mathrm{L} \rightarrow \mathrm{H}$ experiment, the $\alpha^{*}(\lambda)$ values in the blue part of the spectrum increased continuously with time, and the absorption band of zeaxanthin became progressively more marked around $490 \mathrm{~nm}$ (Fig. 3a). The coefficient $a^{\cdot}(445)$ increased by $33 \%$ within $35 \mathrm{~h}$ and then stabilized around $0.064 \mathrm{~m}^{2} \mathrm{mg}^{-1}$ (Fig. 3b), a value close to that observed for the $\mathrm{HH}$ culture (Fig. 3d). This stabilization suggests that the MED strain becomes acclimated to high irradiance conditions within a rather short period $(<2$ d). The increase in $a^{*}(445)$ was parallel to an increase in the zeaxanthin/DV-chl a ratio by a factor of $2(0.35$ to 0.67$)$, while other pigment ratios remained lower than 0.12 , and relatively stable over the duration of the experiment (Table 2). Note that the $a^{*}(445)$ value at the beginning of the experiment $\left(0.048 \mathrm{~m}^{2} \mathrm{mg}^{-1}\right)$ was close to that observed for the same strain at a similar irradiance by Morel et al. (1993) $\left(0.052 \mathrm{~m}^{2} \mathrm{mg}^{-1}\right.$ at $7 \mu \mathrm{mol}$ quanta $\mathrm{m}^{-2}$ $\mathrm{s}^{-1}$, under blue light).

For the MED $H \rightarrow L$ experiment (Fig. 3c), the modification of the $a^{*}(\lambda)$ spectra was, as expected, opposite to that observed during the $\mathrm{L} \rightarrow \mathrm{H}$ transfer. The blue part of the spectrum showed a continuous decrease in amplitude with time, coinciding with a progressive decline (from 0.59 to 0.33 ) of the zeaxanthin/DV-chl a ratio. Other pigment ratios did not exceed 0.10 (Table 2). The coefficient $a^{\bullet}(445)$ decreased abruptly (by approximately 10\%) between 6 and $10 \mathrm{~h}$ after the

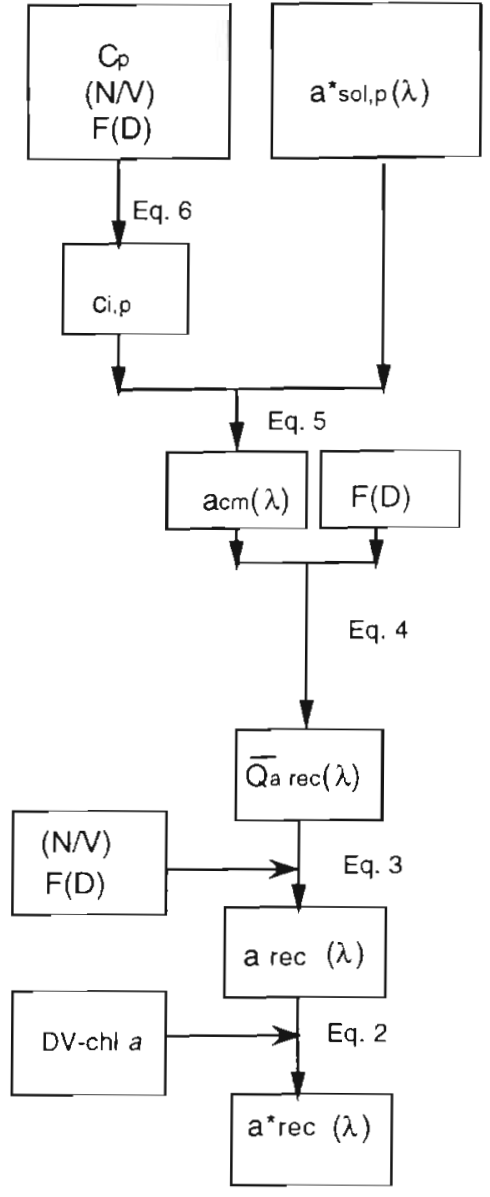

Fig. 2. Flow-chart of the computations for reconstructing the efficiency factors for absorption $\left[\bar{Q}_{\mathrm{arec}}(\lambda)\right]$ and the DV-chl aspecific absorption coefficients $\left[a^{*}{ }_{\text {rec }}(\lambda)\right]$ from the concentrations of individual pigments, their absorption spectra, and the cell size distribution. The definitions of symbols are given in Table 1

transfer, and then more slowly towards a final value of $0.048 \mathrm{~m}^{2} \mathrm{mg}^{-1}$ (Fig. 3d). This value, close to that observed for the LL control culture (Fig. 3b), suggests that photoacclimation was completed over the $4 \mathrm{~d}$ period.

In order to determine whether photoacclimation actually affects the original population or the following generations, the change in cell number densities, $N / V$, during the light transfers was analyzed (Fig. 3b,d). For the $\mathrm{L} \rightarrow \mathrm{H}$ transfer, the specific growth rate $\mu$ (computed for the time interval $\left(t_{2}-t_{1}\right)$ as the ratio $\left[\ln (N / V)_{t_{2}}-\right.$ $\left.\left.\ln (N / V)_{t_{1}}\right\} /\left(t_{2}-t_{1}\right)\right\}$ remained rather low $\left(0.17 \mathrm{~d}^{-1}\right)$ during the first $6 \mathrm{~h}$ and then over the period 6 to $49 \mathrm{~h}$ increased to $0.80 \mathrm{~d}^{-1}$, a value close to that observed for the $\mathrm{HH}$ control culture $\left(0.72 \mathrm{~d}^{-1}\right)$. Such growth rates correspond to 1 doubling per $21 \mathrm{~h}$, and are close to the maximum growth rates observed for natural popula- 

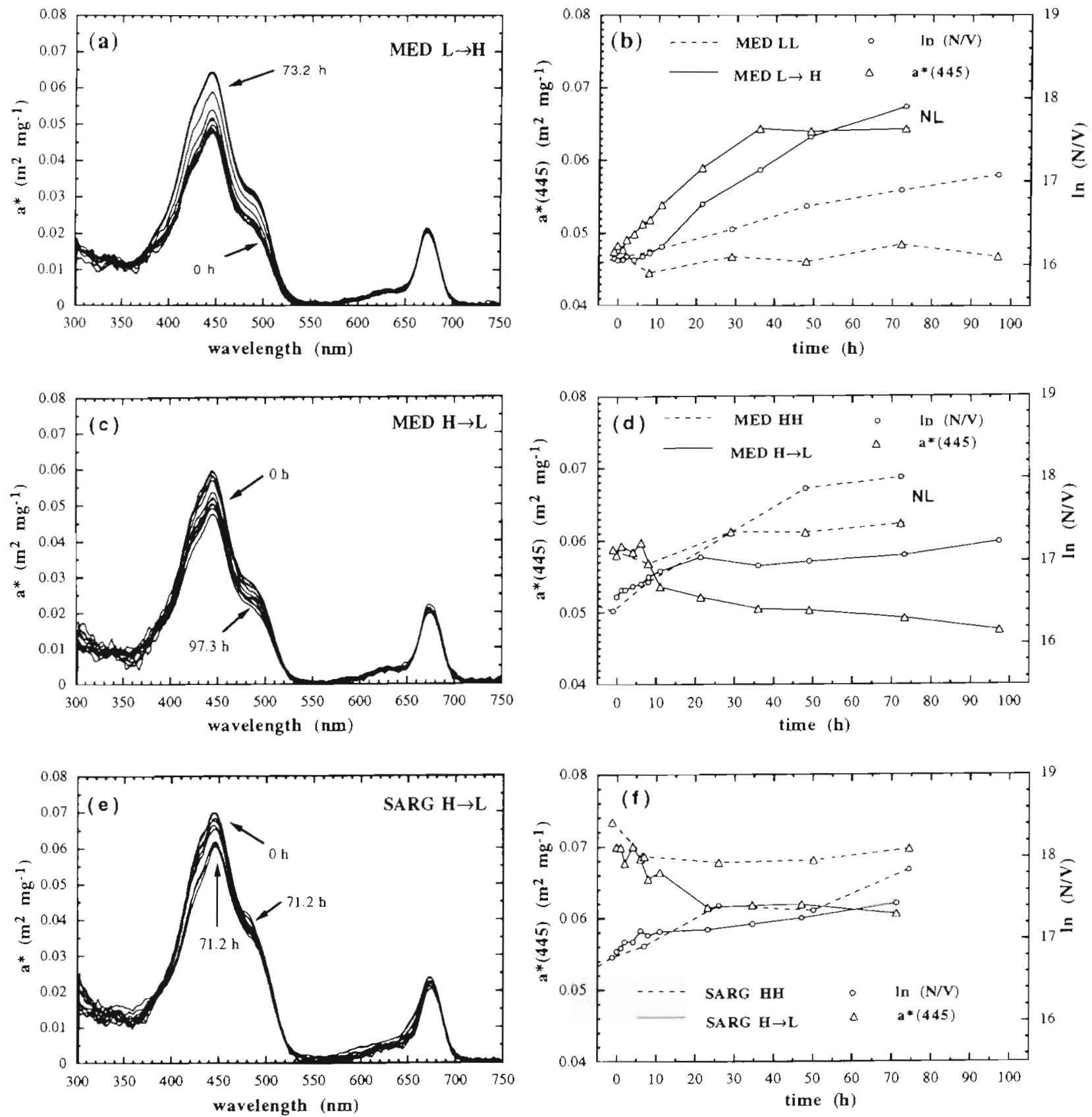

Fig. 3. Prochlorococcus marinus. Left panels: spectral values of DV-chl a-specific absorption coefficients as a function of time, for the 3 experiments - (a) MED strain transferred from low to high irradiance (MED L $\rightarrow$ H), (c) MED strain transferred from high to low ir radiance (MED H $\rightarrow$ L), (e) SARG strain transferred from high to low irradiance (SARG $H \rightarrow L$ ). Right panels: variations of the DV-chl a-specific absorption coefficient at the blue maximum, $a^{*}(445)$, and of the natural logarithm of the cell number density $[\ln (N / V)]$, as functions of time, for the same experiments. Dashed lines: variations corresponding to the control cultures

(LL, HH) (NL: nutrient limitation)

tions in the Equatorial Pacific by Vaulot et al. (1995) Therefore the main change in $a^{\cdot}(\lambda)$ occurs within about 2 generations $(40 \mathrm{~h})$.

For the $\mathrm{H} \rightarrow \mathrm{L}$ transfer experiment, $\mu$ remained (soniewhat surprisingly) at the same level as in the HH control experiment ( 0.66 vs $0.72 \mathrm{~d}^{-1}$ ) for the first
$10 \mathrm{~h}$ following the transfer Then it declined $\left(0.11 \mathrm{~d}^{-1}\right)$, so that over the $4 \mathrm{~d}$ period $\mu$ was on average equal to $0.16 \mathrm{~d}^{-1}$, leading to only 1 doubling over the whole period. In this case, full photoacclimation seems therefore to have been achieved within the same cell generation. 


\section{SARG strain}

For the SARG culture transferred from high to low irradiance $(H \rightarrow L)$, the amplitude of $a^{*}(\lambda)$ spectra progressively decreased, while the chl $b$ bands around 480 and $650 \mathrm{~nm}$ became more marked (Fig. 3e). The $a^{*}(\lambda)$ values were higher than for the MED strain, by approximately $20 \%$ at the blue maximum, consistent with the observations of Moore et al. (1995). The main differences with respect to the MED strain submitted to the same light transfer were (1) a 2- to 4 -fold higher chl $b / \mathrm{DV}$-chl a ratio over the whole period (likely due to the presence of MV-chl b), and (2) a slightly higher zeaxanthin/DV-chl a ratio (Table 2 ). These differences could account for the higher $a^{\bullet}(\lambda)$ values for the SARG strain.

The $a^{\bullet}(445)$ coefficient diminished by $13 \%$ over the whole period (instead of $20 \%$ for the MED $\mathrm{H} \rightarrow \mathrm{L}$ experiment), with the strongest change over the first $25 \mathrm{~h}$ (Fig. 3f), and was accompanied by a $48 \%$ decrease in the zeaxanthin/DV-chl a ratio (Table 2). Conversely, the chl b/DV-chl a ratio increased from 0.21 to 0.48 , while chl $c$ and $\alpha$-carotene remained at low concentrations. Note that the final $a^{*}(445)$ value is rather close to that $\left(0.064 \mathrm{~m}^{2} \mathrm{mg}^{-1}\right)$ measured by Morel et al. (1993) for a similar irradiance.
As shown by the change in cell number density (Fig. 3f), the population remained in active growth $(\mu \approx$ $1 \mathrm{~d}^{-1}$ ) only during the first $6 \mathrm{~h}$ after transfer, then $\mu$ decreased to $0.15 \mathrm{~d}^{-1}$. Over the $3 \mathrm{~d}$ period, $\mu$ was on average $0.20 \mathrm{~d}^{-1}$, which is almost half that of the $\mathrm{HH}$ control culture $\left(0.34 \mathrm{~d}^{-1}\right)$, and corresponds to 1 doubling per $83 \mathrm{~h}$. As for the MED $\mathrm{H} \rightarrow \mathrm{L}$ experiment, the most important change in $a^{*}(\lambda)$ occurs within the first 25 h, i.e. within the same cell generation. In absence of reliable optical measurements for the LL culture, it is difficult to know whether or not acclimation was fully completed within the $3 \mathrm{~d}$ period. The strong variations observed for the intracellular chl $b$ concentration at the end of the experiment (see Fig. 6), however, suggest that the SARG strain was not fully acclimated after $73 \mathrm{~h}$.

\section{Reconstructed efficiency factors for absorption and absorption coefficients}

Examples of reconstructed $a^{*}(\lambda)$ spectra, as compared to experimental spectra, are displayed in Fig. 4. The shape of experimental spectra is fairly well reproduced by theory, and absolute values are also in good agreement between 500 and $700 \mathrm{~nm}$; note in particular the excellent correspondence for the red band (which

Table 2. Prochlorococcus marinus. Values of the divinyl-chl a concentration in the cultures ([DV-chl a]), intracellular DV-chl a concentration $\left.\left(C_{1}, D v_{c h}\right)_{d}\right)$, mean diameter $\left(D_{3}\right)$, pigment ratios (zea: zeaxanthin; $\alpha$-car: $\alpha$-carotene), cell number density $(N / V)$, average specific growth rate $(\mu)$; DV-chl a-specific absorption coefficient at the blue maximum $\left[a^{\circ}(445)\right]$, computed efficiency factor for absorption $\left[\bar{Q}_{d r e c}(445)\right]$ and package effect index at the same wavelength $\left[\bar{Q}_{\mathrm{a}} \cdot(445)\right]$, for the various experiments. Values of the parameters are indicated for the start and end of each experiment. For the control cultures, the minimal and maximal values over the duration of the experiment are indicated

\begin{tabular}{|c|c|c|c|c|c|c|c|c|c|c|c|c|}
\hline Expt & $\begin{array}{l}{[\mathrm{DV}-\mathrm{chl} \mathrm{a}]} \\
\left(\mathrm{mg} \mathrm{m}^{-3}\right)\end{array}$ & $\begin{array}{l}\mathrm{C}_{1, b v \text {-chla }} \\
\left(\mathrm{kg} \mathrm{m}^{-3}\right)\end{array}$ & $\begin{array}{c}D_{3} \\
(\mu \mathrm{m})\end{array}$ & $\begin{array}{c}\text { zea/ } \\
\text { DV-chl a D }\end{array}$ & $\begin{array}{c}\text { chl b/ } \\
\text { DV-chl a }\end{array}$ & $\begin{array}{c}\alpha-c a r / \\
\text { DV-chl a I }\end{array}$ & $\begin{array}{c}\text { chl } d \\
\text { DV-chl a }\end{array}$ & $\begin{array}{l}\mathrm{N} / V\left(10^{7}\right. \\
\left.\text { cell } \mathrm{ml}^{-1}\right)\end{array}$ & $\begin{array}{c}\mu \\
\left(d^{-1}\right)\end{array}$ & $\begin{array}{c}a^{\cdot}(445) \\
\left(\mathrm{m}^{2} \mathrm{mg}^{-1}\right)\end{array}$ & $\begin{array}{l}\bar{Q}_{\mathrm{a} \text { rec }} \\
(445)\end{array}$ & $\begin{array}{c}\overline{Q_{a}} \\
(445)\end{array}$ \\
\hline \multicolumn{13}{|c|}{ MED LL } \\
\hline Min. & 19.5 & 9.3 & 0.72 & 0.32 & 0.05 & 0.10 & 0.02 & 0.96 & & 0.045 & 0.27 & 0.77 \\
\hline Max. & 87.0 & 16.9 & 0.76 & 0.45 & 0.13 & 0.14 & 0.03 & 2.61 & 0.26 & 0.049 & 0.38 & 0.84 \\
\hline \multicolumn{13}{|c|}{ MED HH } \\
\hline Min. & 15.0 & 4.46 & 0.67 & 0.58 & 0.06 & 0.09 & 0.01 & 1.32 & & 0.057 & 0.14 & 0.89 \\
\hline Max. & 57.4 & 6.19 & 0.71 & 0.67 & 0.07 & 0.12 & 0.02 & 6.75 & 0.72 & 0.062 & 0.20 & 0.92 \\
\hline \multicolumn{13}{|c|}{ MED L $\rightarrow \mathrm{H}$} \\
\hline $1.1 \mathrm{~h}$ & 27.9 & 14.07 & 0.74 & 0.35 & 0.1 .0 & 0.11 & 0.02 & 0.94 & & 0.048 & 0.33 & 0.80 \\
\hline $73.2 \mathrm{~h}$ & 57.3 & 5.13 & 0.71 & 0.67 & 0.07 & 0.10 & 0.01 & 5.93 & 0.61 & 0.064 & 0.17 & 0.90 \\
\hline \multicolumn{13}{|c|}{ MED $H \rightarrow L$} \\
\hline $\mathrm{Oh}$ & 19.2 & 6.33 & 0.72 & 0.59 & 0.08 & 0.11 & 0.02 & 1.57 & & 0.058 & 0.20 & 0.88 \\
\hline $97.3 \mathrm{~h}$ & 79.0 & 10.3 & 0.78 & 0.33 & 0.10 & 0.10 & 0.02 & 3.05 & 0.16 & 0.048 & 0.28 & 0.83 \\
\hline \multicolumn{13}{|c|}{ SARGHH } \\
\hline Min. & 14.5 & 3.70 & 0.68 & 0.66 & 0.14 & 0.10 & 0.01 & 1.93 & & 0.068 & 0.14 & 0.86 \\
\hline Max. & 56.5 & 7.26 & 0.80 & 0.87 & 0.28 & 0.16 & 0.02 & 5.64 & 0.34 & 0.073 & 0.24 & 0.92 \\
\hline \multicolumn{13}{|c|}{ SARG $\mathrm{H} \rightarrow \mathrm{L}$} \\
\hline $\mathrm{Oh}$ & 20.0 & 5.58 & 0.69 & 0.71 & 0.21 & 0.13 & 0.01 & 2.07 & & 0.070 & 0.19 & 0.89 \\
\hline $71.2 \mathrm{~h}$ & 61.8 & 9.27 & 0.70 & 0.37 & 0.48 & 0.14 & 0.02 & 3.73 & 0.20 & 0.061 & 0.26 & 0.85 \\
\hline
\end{tabular}




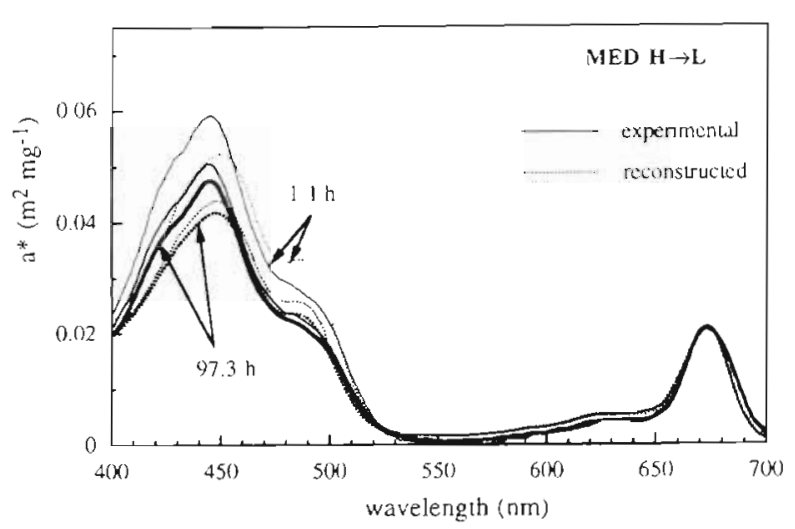

Fig. 4. Prochlorococcus marinus. Examples of experimental and reconstructed spectra of the DV-chl a-specific absorption coefficients, $a^{*}(\lambda)$, for the 2 extreme values (1.1 and $97.3 \mathrm{~h}$ ) and 1 intermediate value $(36 \mathrm{~h})$ of the time scale during the MED $\mathrm{H} \rightarrow \mathrm{L}$ transfer

justifies the assumption made when normalizing absorption spectra; see 'Materials and methods'). Around the blue absorption maximum, the reconstructed values are generally below the experimental values. In spite of this difference, the temporal trends in $a^{*}(445)$ are well reproduced for the various experiments (Fig. 5). When all experiments and all wavelengths are pooled together (not shown), experimental and reconstructed $a^{*}(\lambda)$ values are well correlated $\left(\mathrm{r}^{2}=0.96, \mathrm{~N}=9632\right.$ for MED; $r^{2}=0.95, N=4515$ for SARG), and the slopes of the regression lines are 0.90 and 0.89 , respectively, meaning that the reconstructed values are lower than experimental values by on average $10 \%$.

These differences may originate from various sources: (1) experimental errors in the input parameters used for the theoretical computations (see Fig. 2); (2) deviations from the assumptions (cell sphericity and homogeneity) introduced in these computations; and (3) experimental errors affecting absorption measurements. More specifically, the fact that the underestimation of $a^{*}(\lambda)$ values is essentially confined within the blue domain suggests that it might originate either from an underestimate of carotenoid concentrations, or from an underestimate of some $a^{\circ}{ }_{\text {sol, }}(\lambda)$ coefficients in the blue domain. Some uncertainty remains in particular about the $a^{*}{ }_{\text {sol }}(\lambda)$ coefficients of DV-chl $a$, which vary according to the solvent and the instrumental system ( $\mathrm{H}$. Claustre pers. comm.). Considering these various uncertainties, the agreement (within $10 \%$ ) between experimental and reconstructed $a^{*}(\lambda)$ values can be considered to be satisfactory. This allows us to examine how the various parameters contribute to the $a^{*}(\lambda)$, or equivalently $\bar{Q}_{a}(\lambda)$, variations with time.

The changes in $\overline{Q_{a}}(\lambda)$ with time, as obtained from the reconstruction, are shown in Fig. 6 for the wavelength of the blue maximum. Values of $\bar{Q}_{\mathrm{a}}(445)$ ranged from
0.33 to 0.17 for the MED $\mathrm{L} \rightarrow \mathrm{H}$ experiment, and from 0.15 to 0.30 for the MED $H \rightarrow L$ experiment. For the SARG $H \rightarrow L$ experiment, $\bar{Q}_{a}(445)$ spanned a similar range of values $(0.16$ to 0.26$)$. Note that the values corresponding to low-light conditions are consistent with those determined (for an irradiance of $7 \mu \mathrm{mol}$ quanta $\mathrm{m}^{-2} \mathrm{~s}^{-1}$ ) by Morel et al. (1993) (0.23 to 0.37 for MED, 0.21 to 0.25 for SARG). These relatively high values indicate a non-negligible package effect, as will be shown later

The variations of the parameters responsible for the $\bar{Q}_{\mathrm{a}}(\lambda)$ variations are shown in Fig, $6 \mathrm{~b}, \mathrm{~d}, \mathrm{f}$. For the MED strain, the main source of variation for $\bar{Q}_{d}(\lambda)$ appears to be the intracellular concentration of DV-chl $a$, which decreased 3 -fold during the $\mathrm{L} \rightarrow \mathrm{H}$ transfer, and
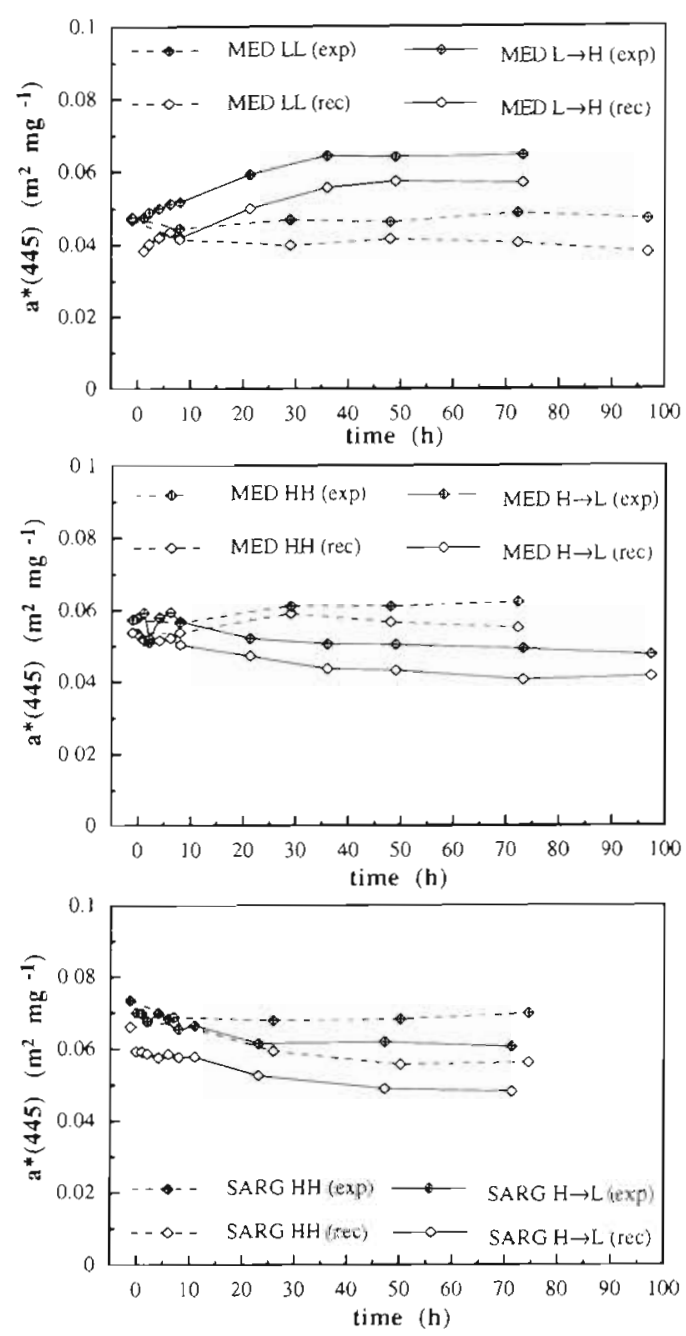

Fig. 5. Prochlorococcus marinus. Variations with time of the experimental (exp) values of DV-chl a-specific absorption coefficients at the blue maximum, $\alpha^{*}(445)$, as compared to reconstructed (rec) values, for the 3 light-shift experiments. Dashed lines: corresponding values for the control cultures 

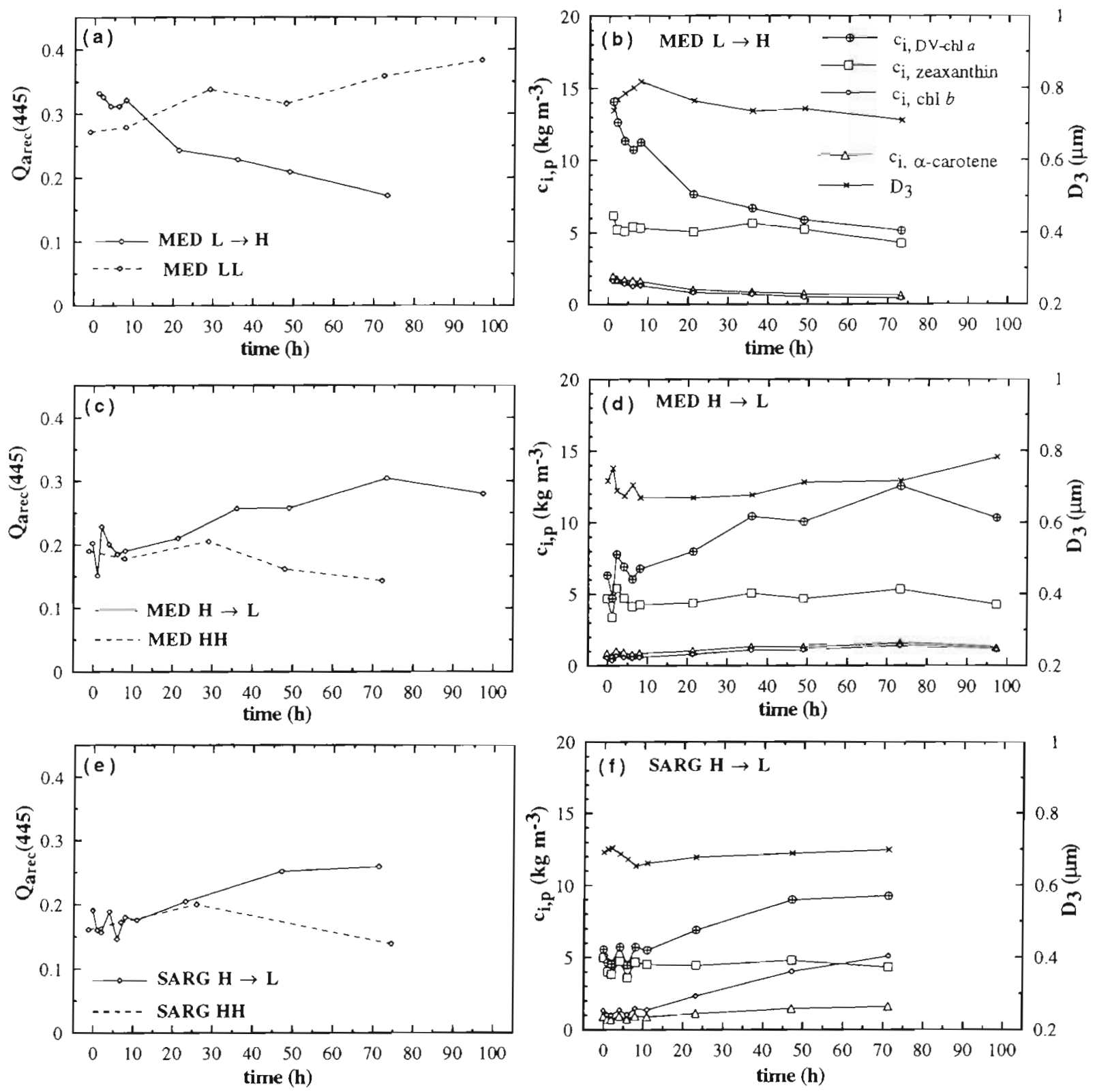

Fig. 6. Prochlorococcus marinus. Left panels: reconstructed values of the efficiency factors at the blue maximum, $\bar{Q}_{\mathrm{a}}(445)$, as functions of time, for the 3 experiments. Dashed lines: corresponding values for the control cultures. Right panels: changes with time in the intracellular concentrations of the main pigments $\left(c_{\mathrm{i}, \mathrm{p}}\right.$ left scales) and in the mean cell diameter ( $D_{3}$, right scales), for the same experiments. The corresponding curves for the control cultures have been omitted for clarity. The intracellular chl $b$

concentration pertains to DV-chl $b$ only for the MED strain (b,d), and to the sum (chl $b+\mathrm{DV}$-chl $b$ ) for the SARG strain (f)

increased 2-fold during the inverse transfer. The intracellular concentration of zeaxanthin was remarkably constant and insensitive to the light transfers, so that the variations of the zeaxanthin/DV-chl a ratio, previously noted, stemmed essentially from the $c_{i, D v}$-chl a variations. The main effect of zeaxanthin was therefore to enhance the $\overline{Q_{a}}(\lambda)$ values (via the $a_{c m}(\lambda)$ coefficients, see Eq. 4), and thus to reduce the effect of $C_{\mathrm{i}, D V}$-chl $a$ variations, by increasing the general 'level' of $a_{\mathrm{cm}}(\lambda)$ whatever the irradiance conditions. Intracellular concentrations of other pigments, which were 1 order of magnitude lower than that of DV-chl $a_{1}$ contributed very little to $a_{\mathrm{cm}}(\lambda)$ and $\bar{Q}_{\alpha}(\lambda)$ variations with time. The mean cell size showed only very weak variations (e.g. 0.82 to $0.71 \mu \mathrm{m}$ for the $\mathrm{L} \rightarrow \mathrm{H}$ transfer), which had a negligible impact upon the $\overline{Q_{a}}(\lambda)$ variations.

For the SARG strain, similar trends were observed as a result of the $\mathrm{H} \rightarrow \mathrm{L}$ transfer, namely the increase 
of $C_{1, \text { DV }}$-chl a by a factor of 2 , the stability of the intracellular concentration of zeaxanthin and no significant variation in the cell size (Fig. 6f). Conversely to the MED strain, the intracellular concentration of DV-chl $b+\operatorname{chl} b$ was always significant, and increased by more than a factor of 4 during the experiment. Therefore the presence of these pigments contributed here not only to enhance the $\overline{Q_{a}}(\lambda)$ values in all light conditions, but also to reinforce the effect of $c_{\mathrm{j}, \mathrm{DV}-\mathrm{chl}}$ variations during photoacclimation.

\section{The package effect in Prochlorococcus and the} implications for its photosynthetic performance

For the range of $\overline{Q_{a}}(\lambda)$ values estimated above for both strains $(0.15$ to 0.33$)$, the $\overline{Q_{a}}(\lambda)$ versus $\rho^{\prime}$ relationship (Eq. 4) departs from linearity (see Fig. 1 in Morel \& Bricaud 1981), which suggests that in these experiments Prochlorococcus cells underwent a non-negligible package effect. A quantitative evaluation of this effect (and of the consequences upon the absorption capacity of cells) for the various experiments can be made by computing the 'package effect index', $\bar{Q}_{\mathrm{a}} \cdot(\lambda)$.
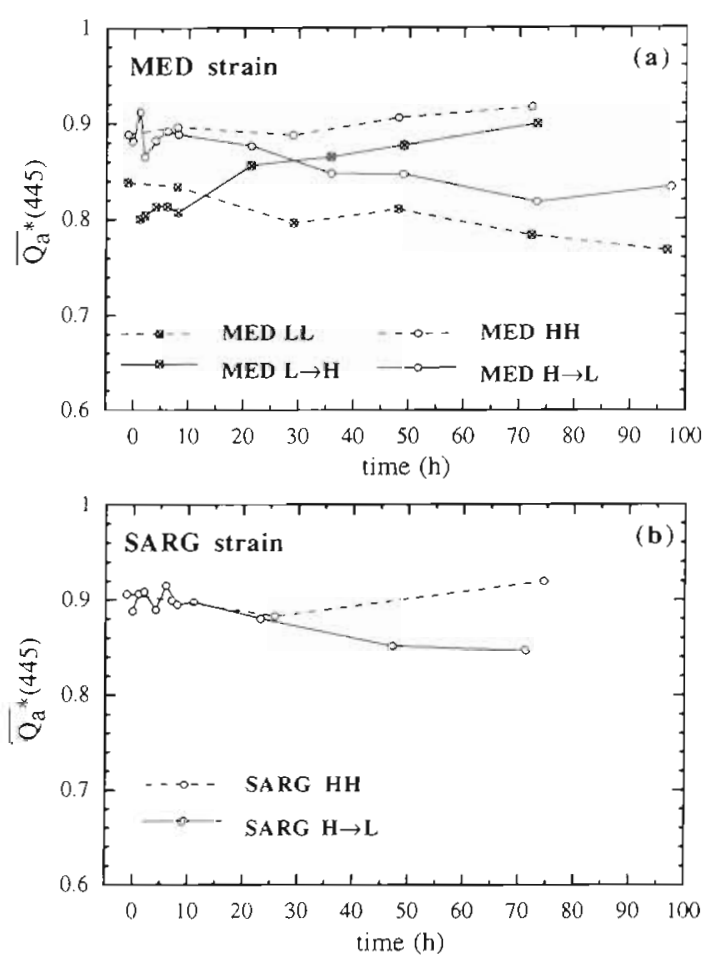

Fig. 7 Prochlorococcus marinus. Variations of the package effect index at $445 \mathrm{~nm}, \bar{Q}_{a} \cdot(445)$, (a) for the MED strain transferred from low to high urradiance $(\mathrm{L} \rightarrow \mathrm{H})$ and from high to low irradiance $(H \rightarrow L)$, and (b) for the SARG strain transferred from high to low irradiance $(\mathrm{H} \rightarrow \mathrm{L})$. Dashed lines: values corresponding to the control cultures (LL, HH)
This index is defined as the ratio of $a^{*}(\lambda)$ to the specific absorption coefficient of the same material ideally dispersed into solution (Morel \& Bricaud 1981), and decreases from 1 (no package effect) to 0 (maximal package effect). For a given wavelength and size, $Q_{a}{ }^{*}(\lambda)$ can be computed from $a_{\mathrm{cm}}(\lambda)$ and $D$ [Eqs. $1 \& \sigma$ in Morel \& Bricaud 1981, with $\left.\rho^{\prime}=a_{\mathrm{cm}}(\lambda) D\right]$; then, for the actual size distribution, $\bar{Q}_{\mathrm{a}}{ }^{*}(\lambda)$ is derived by averaging according to $F(D)$.

At high irradiance, $\bar{Q}_{a} \cdot(445)$ is around 0.90 for both strains, which means that the maximal absorption capacity of pigments is depressed by $10 \%$. At low irradiance, $\overline{Q_{a}} \cdot(445)$ decreases only to 0.85 for the SARG strain, but down to $0.77-0.83$ for the MED strain (Fig. 7). Note that if, as hypothetized above, carotenoid concentrations and/or $a^{*}$ sol $(\lambda)$ coefficients used in theoretical computations are underestimated (both leading to an underestimate of $\mathrm{a}_{\mathrm{cm}}$ ), then the actual ${\overline{Q_{a}}}^{*}\left(\lambda_{\mathrm{c}}\right)$ values will be still lower and the package effect will be reinforced.

The range of values observed here for ${\overline{Q_{a}}}(445)$ is rather narrow, because the range of variation of irradiance was restricted with respect to the expected in situ values. The 'high' and 'low' irradiances used in these experiments correspond to approximately $10 \%$ and $1 \%$ of the (24 h averaged) surface irradiance in waters where Prochlorococcus is found (Cailliau et al. 1996). Near the surface (where $C_{i}$, DV-chl a is probably still. lower than the values measured here at 'high' irradiance), the $\bar{Q}_{a} \cdot(445)$ values are expected to be close to 1 , and the package effect to be insignificant for Prochlorococcus. In contrast, in light regimes prevailing at the bottom of the euphotic zone, and below the $1 \%$ light level. the package effect could reduce the absorption efficiency of Prochlorococcus (per unit of DV-chl a) by as much as 20 to $25 \%$.

This decrease in $\overline{Q_{a}} \cdot(\lambda)$ corresponds to a decrease in the amount of absorbed energy usable for photosynthesis (when expressed with respect to the DV-chl a content), and ultimately in the photosynthetic performance of Prochlorocaccus cells when they travel from high-light to low-light environments. This decrease in absorbed energy can be compared with that resulting from the decreasing contribution of zeaxanthin to the overall absorption. From Eq. (5), the contribution of zeaxanthin to the total $a_{\mathrm{cm}}(\lambda)$ value (at $445 \mathrm{~nm}$ ) is estimated to decrease from 41 to $28 \%$ for the MED $\mathrm{H} \rightarrow \mathrm{L}$ transfer (with a symmetric increase, from 29 to $45 \%$, for the inverse transfer). These proportions are virtually the same for the SARG $H \rightarrow L$ transfer ( 44 and $27 \%$, respectively). These results compare well with those obtained by Moore et al. (1995) under similar light conditions. It is recalled here that the presence of zeaxanthin (a non-photosynthetic pigment) has no direct effect upon the amount of energy usable for photosyn- 
thesis. However, it intervenes in an indirect way, by enhancing $\bar{Q}_{\mathrm{a}}(\lambda)$ (i.e. by reinforcing the package effect) under all light conditions.

It is interesting to compare the changes in the package effect observed for Prochlorococcus with those occurring for other phytoplanktonic groups. Many studies have evidenced the changes in cellular pigment contents and composition with photoacclimation, for a wide range of algal species (see e.g. the reviews by Falkowski \& LaRoche 1991, Kirk 1994). However, these changes have been seldom analyzed in terms of absorption coefficients or efficiency factors. Absorption measurements made at various irradiances by Falkowski et al. (1985), Morel et al. (1987) and Mitchell \& Kiefer (1988) on large algal species, have evidenced variations in $\bar{Q}_{\dot{\alpha}} \cdot(675)$ by at least a factor of 2 (no estimate of $\bar{Q}_{\vec{a}} \cdot(\lambda)$ in the blue part of the spectrum can be inferred from these studies, because of associated changes in the pigment composition). A direct assessment of the packaging effect at $445 \mathrm{~nm}$ can be inferred from the study of Berner et al. (1989), who measured absorption coefficients for cultures of the chlorophyte Dunaliella tertiolecta acclimated at 700 and $70 \mu \mathrm{mol}$ quanta $\mathrm{m}^{-2} \mathrm{~s}^{-1}$, before and after solubilization of thylakoid membranes in a non-ionic detergent. From their measurements, $\bar{Q}_{\diamond} \cdot(445)$ is found to vary from 0.92 for the cuiture acclimated at $700 \mu \mathrm{mol}$ quanta $\mathrm{m}^{-2} \mathrm{~s}^{-1}$, to 0.55 at $70 \mu \mathrm{mol}$ quanta $\mathrm{m}^{-2} \mathrm{~s}^{-1}$ (their Fig. 1). It is obviously not surprising that for large algal species $\bar{Q}_{a} \cdot(445)$ encompasses a much wider range than for Prochlorococcus

\section{CONCLUSIONS}

Both MED and SARG strains of Prochlorococcus undergo significant changes in their DV-chl a -specific absorption coefficients, $a^{*}(\lambda)$, in response to light variations. The MED strain, in particular, appears to be the most sensitive to the radiative level, with a decrease of $a^{*}(\lambda)$ at the blue maximum (445 $\mathrm{nm}$ ) by $20 \%$ when transferred from high to low irradiance. It is worth recalling that the 'high' irradiance $(56.7 \mu \mathrm{mol}$ quanta $\mathrm{m}^{-2} \mathrm{~s}^{-1}$ ) is well below the radiative levels possibly encountered in the near-surface, well-lit layers (up to 1000-1500 $\mu \mathrm{mol}$ quanta $\mathrm{m}^{-2} \mathrm{~s}^{-1}$ at noon); therefore the range encompassed by $a^{\cdot}(\lambda)$ is expected to be much larger for natural populations of Prochlorococcus, in agreement with previous observations in oligotrophic waters (Babin et al. 1996, Allali et al. 1997). For a given light regime, chl-specific absorption coefficients are on average higher for the SARG strain than for the MED strain, essentially as a result of higher DV-chl $b$ contents (and the presence of MV-chl b) and higher zeaxanthin/DV-chl a ratios.
Experiments on photoacclimation kinetics suggest that for the MED strain photoacclimation is achieved within approximately $40 \mathrm{~h}$ (2 cell generations) for the low to high irradiance transfer and 3 to $4 \mathrm{~d}$ (1 cell generation) for the inverse transfer. For the SARG strain transferred from high to low irradiance, the $3 \mathrm{~d}$ period was seemingly insufficient for full photoacclimation. These rather long photoacclimation periods observed for absorption, support the conclusions of Babin et al. (unpubl.) that Prochlorococcus possesses only 1 main photoacclimation strategy, effective at a time scale of a few days. These authors suggest that this might help to explain why Prochlorococcus dominates oligotrophic, well-stratified systems, but not eutrophic waters, where cells have to face short-term variations in irradiance.

The variations of $a^{*}(\lambda)$ observed during photoacclimation for the 2 strains were reproduced by theory within a reasonable degree of accuracy using the cell characteristics (intracellular concentrations of the various pigments and cell size distribution) as input parameters. Therefore, the respective contributions of these various parameters to the variations in $a^{*}(\lambda)$ and $\overline{Q_{a}}(\lambda)$ with time were quantified. As the intracellular DV-chl a concentration varies widely, whereas that of zeaxanthin remains stable whatever the light conditions, this non-photosynthetic pigment is, by virtue of normalization to DV-chl a, the major source of variability in $a^{*}(\dot{\lambda})$. This does not mean, however, that the amount of 'photosynthetically efficient' absorbed energy is the same at all irradiances. The $\overline{Q_{a}}(\lambda)$ values, and therefore the package effect, are enhanced at low irradiance by 2 factors: (1) the notable increase of the intracellular concentration of DV-chl a, and (2) for the SARG strain only, the increase of the intracellular concentrations of chl $b$ and DV-chl $b$ (variations in cell size, which could also have influenced $\overline{Q_{a}}(\lambda)$, have been found to be insignificant). These factors entail some reduction ( 20 to $25 \%$ ) of the light absorption efficiency of Prochlorococcus (per unit of DV-chl a) for the irradiances prevailing in the lower part of the euphotic zone. The effect of zeaxanthin is actually to enhance the $\overline{Q_{a}}(\lambda)$ values under all light conditions, and therefore to reinforce the package effect and to make it less variable with irradiance (i.e. along the verticaly than it would be in the absence of this pigment.

Acknowledgements. This paper is a contribution to the Prochlorococcus workshop organized in Roscoff with the financial support of CNRS-GDR 869, JGOFS-France, INSU and Région Bretagne. The support of the EC PROMOLEC program (MAS3CT97-0128) is also duly acknowledged. We thank $V$ Martin-Jézéquel for help in organizing the workshop, R. Casotti and N. Simon for help in preparing cultures and sampling, G. W. Kraay for contributing to pigment measurements, $\mathrm{H}$. Claustre for providing absorption spectra of 
individual pigments measured by HPLC, and M. Babin and D. Stramski for comments on earlier drafts of the manuscript. We thank the 3 referees for thorough comments.

\section{LITERATURE CITED}

Allali K, Bricaud A, Claustre H (1997) Spatial variations in the chlorophyll-specific absorption coefficients of phytoplankton and photosynthetically active pigments in the Equatorial Pacific. J Geophys Res 102:12413-12423

Babin M, Morel A, Claustre H, Bricaud A, Kolber Z, Falkowski PG (1996) Nitrogen- and irradiance-dependent variations of the maximum quantum yield of carbon fixation in eutrophic, mesotrophic and oligotrophic marine systems. Deep-Sea Res 43(8):1241-1272

Berner T, Dubinsky Z, Wyman K, Falkowski PG (1989) Photoadaptation and the 'package' effect in Dunaliella tertiolecta (Chlorophyceae). J Phycol 25:70-78

Bidigare RR, Smith RC, Baker KS, Marra J (1987) Oceanic primary production estimates from measurements of spectral irradiance and pigment concentrations. Global Biogeochem Cycles 1:171-186

Bidigare RR, Ondrusek ME, Morrow JH, Kiefer DA (1990) In vivo absorption properties of algal pigments. In: Ocean optics X, Proc Soc Photo-Opt Instrum Eng Vol 1302, p $290-302$

Cailliau C, Claustre H, Vidussi F, Marie D, Vaulot D (1996) Carbon biomass, and gross growth rates as estimated from ${ }^{14} \mathrm{C}$ pigment labelling, during photoacclimation in Prochlorococcus CCMP 1378. Mar Ecol Prog Ser 145:209-221

Campbell L, Vaulot D (1993) Photosynthetic picoplankton community structure in the subtropical central North Pacific Ocean (station ALOHA). Deep-Sea Res 40: 2043-2060

Campbell L, Nolla HA, Vaulot D (1994) The importance of Prochlorococcus to community structure in the central North Pacific Ocean. Limnol Oceanogr 39:954-961

Chisholm SW, Olson RJ, Zettler ER, Goericke R. Waterbury JB, Welschmeyer NA (1988) A novel free-living prochlorophyte abundant in the oceanic euphotic zone. Nature 334: $340-343$

Demmig-Adams B (1990) Carotenoids and photoprotection in plants: a role for the xanthophyll zeaxanthin. Biochem Biophys Acta 1020:1-24

Falkowski PG, LaRoche J (1991) Acclimation to spectral irradiance in algae. J Phycol 27:8-14

Falkowski PG, Dubinsky Z, Wyman K (1985) Growth-irradiance relationships in phytoplankton. Limnol Oceanogr 30: 311-321

Goericke R, Repeta DJ (1993) Chlorophylls $a$ and $b$ and divinyl-chlorophylls $a$ and $b$ in the open subtropical North Atlantic Ocean. Mar Ecol Prog Ser 101:307-313

Goericke R, Welschmeyer NA (1993) The marine prochlorophyte Prochlorococcus contributes significantly to phytoplankton biomass and primary production in the Sargasso Sea. Deep-Sea Res 40:2283-2294

Keller MD, Selven RC, Claus W. Guillard RRL (1987) Media for the culture of oceanic ultraphytoplankton. J Phycol 23: $633-638$

Kirk JTO (1994) Light and photosynthesis in aquatic ecosystems. Cambridge University Press, Cambridge

Kraay GW, Zapata M, Veldhuis MJW (1992) Separation of chlorophylls c1, c2 and $c 3$ of marine phytoplankton by reversed-phase-C18-high-performance liquid chromatography. J Phycol 28:708-712

Latasa M, Bidigare RR, Ondrusek ME, Kennicut MC Il (1996) HPLC analysis of algal pigments: a comparison exercise among laboratories and recommendations for improved analytical performance. Mar Chem 51:315-324

Lindley S, Bidigare RR, Barber RT (1995) Phytoplankton photosynthesis parameters along $140^{\circ} \mathrm{W}$ in the Equatorial Pacific. Deep-Sea Res 42:441-463

Mitchell BG, Kiefer DA (1988) Chlorophyll a-specific absorption and fluorescence excitation spectra for light-limited phytoplankton. Deep-Sea Res 35(5):639-663

Moore LR, Goericke R, Chisholm SW (1995) Comparative physiology of Synechococcus and Prochlorococcus: influence of light and temperature on growth, pigments, fluorescence and absorptive properties. Mar Ecol Prog Ser 116:259-275

Morel A, Bricaud A (1981) Theoretical results concerning light absorption in a discrete medium, and application to specific absorption of phytoplankton. Deep-Sea Res 28 $1375-1393$

Morel A, Bricaud A (1986) Inherent optical properties of algal cells including picoplankton: theoretical and experimental results. In: Photosynthetic picoplankton. Can Bull Fish Aquat Sci 214:521-559

Morel A, Lazzara L, Gostan J (1987) Growth rate and quantum yield time response for a diatom to changing irradiances (energy and color). Limnol Oceanogr 32:1066-1084

Morel A, Ahn YH, Partensky F, Vaulot D, Claustre H (1993) Prochlorococcus and Synechococcus: a comparative study of their optical properties in relation to their size and pigmentation. J Mar Res 51:617-649

Palenik BP, Haselkorn R (1992) Multiple evolutionary origins of prochlorophytes, the chlorophyll $b$-containing prokaryotes. Nature 355:265-267

Partensky F, Hoepffner N, Li WKW, Ulloa O, Vaulot D (1993) Photoacclimation of Prochlorococcus sp. (Prochlorophyta) Strains Isolated from the North Atlantic and the Mediterranean Sea. Plant Physiol (Rockv) 101:285-296

Partensky F, Blanchot $\mathbf{J}$, Lantoine $F$, Neveux J, Marie D (1996) Vertical structure of picophytoplankton at different trophic sites of the subtropical northeastern Atlantic Ocean. Deep-Sea Res 43:1191-1213

Partensky F, Hess WR, Vaulot D (1999) Prochlorococcus, a marine photosynthetic prokaryote of global significance. Microbiol Mol Biol Rev 63(1):106-127

Smith RC, Prézelin BB, Bidigare RR, Baker KS (1989) Biooptical modeling of photosynthetic production in coastal waters. Limnol Oceanogr 34:1524-1544

van de Hulst HC (1957) Light scattering by small particles. Wiley-Liss, New York

Vaulot D, Courties C. Partensky F (1989) A simple method to preserve oceanic phytoplankton for flow cytometric analyses. Cytometry 10:629-635

Vaulot D, Marie D, Olson RJ, Chisholm SW (1995) Growth of Prochlorococcus a, photosynthetic prokaryote, in the Equatorial Pacific Ocean. Science 268:1480-1482

Veldhuis MJW, Kraay GW (1990) Vertical distribution and pigment composition of a picoplanktonic prochlorophyte in the subtropical North Allantic: a combined study of HPLC-analysis of pigment and flow cytometry. Mar Ecol Prog Ser 68:121-127

Submitted: July 8, 1997; Accepted: May 7, 1999

Proofs received from author(s): October 18, 1999 